\title{
SERVIÇO SOCIAL E SUPERVISÃO DE VIGILÂNCIA EM SAÚDE (SUVIS): CONSTRUÇÃO DE IDENTIDADES
}

\author{
SOCIAL WORK AND SUPERVISION OF HEALTH SURVEILLANCE: IDENTITIES \\ CONSTRUCTION
}

\author{
Bianca Ribeiro de Souza ${ }^{1}$ \\ Rosangela Helena Pezoti ${ }^{2}$
}

\section{RESUMO}

O presente artigo pontua as principais reflexões apreendidas a partir de pesquisa qualitativa ${ }^{3}$ realizada com assistentes sociais inseridos nas Supervisões de Vigilância em Saúde (SUVIS's) de uma dada região da cidade de São Paulo. Tal estudo aborda como se deu a inserção dos profissionais neste espaço, quais são os trabalhos desenvolvidos, bem como discute a construção histórica da identidade profissional do Serviço Social e como esta se delineia no campo de trabalho específico da SUVIS.

PALAVRAS-CHAVE: Vigilância em Saúde. Serviço Social. Espaço ocupacional. Identidade.

\begin{abstract}
This article presents the main reflections realized from qualitative research with social workers who work at Supervision of Health Surveillance in a specific region of São Paulo city. This study approaches how was the inclusion of professionals at this workplace, which tasks are currently developed, as well as discusses the historical construction of professional identity of Social Work and how this identity is expressed at Supervision of Health Surveillance.
\end{abstract}

KEYWORDS: Health Surveillance. Social Work. Workplace. Identity.

\section{INTRODUÇÃO}

No ano de 2008, um número considerável de assistentes sociais ingressou na Prefeitura de São Paulo, através de concurso público, sendo que a Secretaria Municipal de Saúde foi a primeira instância a nomear os candidatos que comporiam o seu quadro de funcionários.

\footnotetext{
${ }^{1}$ Assistente Social, mestranda em Serviço Social: Pontif cia Universidade Cat lica de S o Paulo (PUCSP), com Especializaç o em Serviço Social: Direitos Sociais e Compet ncias Profissionais, CFESS/ A EPSS/CEAD da Un .Telefone 11 98222-3608, e-mail iarsouza@hotmail.com.

${ }^{2}$ Doutoranda em Serviço Social, pela Pontif cia Universidade Cat lica de S o Paulo (PUC-SP). E-mail pezoti@uol.com.r.

${ }^{3}$ Monografia apresentada ao Curso de Especializaç o "Serviço Social: Direitos Sociais e Compet ncias Profissionais" CFESS/ A EPSS/ CEAD da Un , Serviço Social e Supervis o de igil ncia em Saúde (SU IS): construç o de identidades. ras lia, 2010.

Serv. Soc.\& Saúde, Campinas, SP v. 11, n. 2 (14) p. 223-244 jul./ dez. 2012 ISSN 1676-6806
} 
Dentre as vagas disponíveis, estavam aquelas que tradicionalmente são lócus de trabalho da categoria, por exemplo, as Unidades Básicas de Saúde (UBS) e os Hospitais. Por outro lado, foi apresentada a possibilidade de inserção dos profissionais nas Supervisões de Vigilância em Saúde (SUVIS's).

As SUVIS's são unidades descentralizadas da Coordenação de Vigilância em Saúde (COVISA) ${ }^{4}$, localizadas nas cinco regiões administrativas da cidade - Norte, Sul, Leste, Centro-Oeste e Sudeste. Ao todo são 26 Supervisões cuja área de intervenção se materializa no âmbito da Vigilância Sanitária, da Vigilância Epidemiológica e da Vigilância Ambiental ${ }^{5}$.

No que concerne às ações cotidianas desenvolvidas nas Supervisões, podemos caracterizá-las da seguinte forma:

- Na Vigilância Sanitária são operacionalizadas inspeções que orientam e fiscalizam a execução das boas práticas em estabelecimentos que comercializam produtos e/ou prestam serviços relacionados à saúde, tais como: bares, restaurantes, padarias, drogarias, consultórios, Instituições de Longa Permanência para Idosos (ILPI's), creches e institutos de beleza. A Vigilância Sanitária tem livre acesso a qualquer serviço e possui a autonomia de impor penalidades, como a interdição total do estabelecimento, caso ofereça risco iminente à saúde da coletividade. Os profissionais atuantes neste segmento são de diversificadas áreas, como médicos, enfermeiros, assistentes sociais, dentistas, nutricionistas, farmacêuticos, veterinários, biólogos, arquitetos e etc. No entanto, para o desempenho das atividades de vigilância é necessário que o agente fiscalizador seja nomeado, pelo Secretário Municipal da Saúde, como Autoridade Sanitária.

- Na Vigilância Epidemiológica são desenvolvidos diversos programas importantes na prevenção e no controle de doenças, quais sejam: o tratamento e prevenção da Tuberculose e das Doenças Sexualmente Transmissíveis (DST's), o controle da Hanseníase e da Dengue; imunizações; investigações de surtos de doenças

\footnotetext{
${ }^{4}$ De acordo com o Decreto n 50.079, de 07/10/2008, da cidade de S o Paulo, as SU IS s, em conjunto com a Coordenaç o de igil ncia em Saúde (CO ISA) e os Centros de Refer ncia em Saúde do Tra alhador (CRST s), comp em o Sistema Municipal de igil ncia em Saúde - SM S. Estas tr s esferas s o inst ncias administrativas regionais respons veis pela operacionalizaç o do chamado Direito Sanit rio, cujas premissas ser o es oçadas a seguir.

${ }^{5}$ O Artigo 6 da Lei Federal n 8.080/90 define as aç es referentes s igil ncias Sanit ria e Epidemiol gica, j a Lei Municipal n 13.725/04 C digo Sanit rio do Munic pio de S o Paulo, em seu Artigo 2 , disp e so re as aç es de igil ncia Am iental. Serv. Soc. \& Saúde, Campinas, SP v. 11, n. 2 (14) p. 223-244 jul./dez. 2012 ISSN 1676-6806
} 
emergentes; gerenciamento do sistema de informações de doenças de notificação compulsória, entre outros.

- Na Vigilância Ambiental são executadas ações específicas de prevenção e controle das zoonoses e enfermidades transmitidas por vetores, como exemplo, podemos citar, o serviço de vistoria zoossanitária que, segundo o site da Prefeitura de São Paulo, tem como objetivo diminuir os riscos à saúde humana, ocasionados pela convivência homem-animal inadequada, bem como evitar que os animais sejam submetidos a abusos ou maus-tratos.

Cabe ressaltar que um número reduzido de assistentes sociais, admitidos em concursos anteriores, já desenvolvia práticas cotidianas em algumas SUVIS's, no entanto, tal intervenção não era conhecida pelo conjunto da categoria. Deste modo, com a inserção considerável de profissionais, a partir do ano de 2008, este "novo" espaço sócio ocupacional ganha destaque e, concomitantemente, emergem questionamentos sobre os desafios e possibilidades desta inserção.

Face ao exposto, esta temática teve o objetivo geral de apontar como se delineia a identidade profissional dos assistentes sociais inseridos nas SUVIS's. Já os objetivos específicos se sustentaram em verificar como se deu a inserção dos profissionais neste espaço e quais são os trabalhos desenvolvidos atualmente, bem como se buscou compreender a construção histórica da identidade profissional do Serviço Social.

Como fundamento teórico ${ }^{6}$ para a realização do presente estudo, foi abordado, primeiramente, a organização da política de saúde no Brasil, desde a República Velha (1889-1930) até a composição do Sistema Único de Saúde (SUS), o qual é instituído pela Constituição da República Federativa do Brasil de 1988.

Com o reconhecimento da saúde como direito, instituído pela Constituição de 1988, as questões relacionadas com a saúde da população, segundo Aith (2007), passaram a ser monitoradas, medidas e reguladas de forma sistematizada pela esfera do Direito. Neste sentido, vislumbra-se o chamado Direito Sanitário, o qual é suscitado pelo diálogo relacional entre o Direito e a saúde.

O Direito Sanitário é a leitura jurídica que a sociedade faz sobre a questão da saúde, individual ou coletiva; resulta, portanto, dos esforços da sociedade para organizar um conjunto de normas jurídicas capaz de tornar previsíveis as atividades relacionadas com a promoção, a proteção e a recuperação da saúde no país. Ele é

\footnotetext{
${ }^{6}$ Devemos salientar ue durante a e ecuç o deste tra alho $\mathrm{n}$ o foram encontradas i liografias so re a tem tica es oçada, logo, a elucidaç o de alguns uestionamentos se revelou como o grande desafio desta pes uisa.

Serv. Soc.\& Saúde, Campinas, SP v. 11, n. 2 (14) p. 223-244 jul./ dez. 2012 ISSN 1676-6806
} 
orientado a regular e direcionar tais atividades para garantir a todos a realização do Direito à saúde [...] (AITH, 2007, p. 88).

Para que o Estado materialize a efetivação deste direito social ${ }^{7}$, é premente que sejam considerados dois tipos de obrigação estatal, isto é, aquelas relacionadas com a saúde pública e outros referentes à saúde individual.

Neste sentido, o cumprimento das supracitadas obrigações será viabilizado através de "[...] instrumentos jurídicos eficazes e capazes de oferecer ao gestor público as ferramentas necessárias às ações concretas em busca da redução dos riscos à saúde" (BRASIL, MINISTÉRIO DA SAÚDE, 2006, p. 97). Dentre estes instrumentos, que compõem o Direito Sanitário, podemos citar: a Lei Orgânica da Saúde; o Sistema Único de Saúde; os variados Códigos Sanitários estaduais e municipais; as Leis de criação das Agências Nacionais de Vigilância Sanitária e de Saúde Suplementar, além dos regulamentos que dispõem sobre o funcionamento de ações e serviços de interesse à saúde.

De acordo com o Ministério da Saúde (2006), o princípio fundamental que se circunscreve na esfera do Direito Sanitário, refere-se à responsabilidade, cuja premissa estabelece que todos os cidadãos têm deveres com relação à proteção da saúde, sejam individuais, coletivos e sociais. Tal princípio é essencial para a segurança sanitária do conjunto da população, visto que "[...] atinge tanto os comportamentos privados e íntimos quanto seus comportamentos sociais e públicos" (BRASIL, MINISTÉRIO DA SAÚDE, 2006, p. 107).

Dentre os instrumentos jurídicos utilizados pelo Direito Sanitário, é mister indicarmos a função da Lei Federal n. 9.782/99 que dispõe sobre o Sistema Nacional de Vigilância Sanitária (SNVS), destinado a eliminar, diminuir ou prevenir riscos à saúde. Conforme Dallari e Júnior (2010), o SNVS institui-se como complemento aos mandamentos constitucionais e legais que organizam o Sistema de Saúde no Brasil, propondo ações integradas entre as três esferas de governo (União, Estados e Municípios).

Historicamente, quando precisamos nos reportar ao órgão responsável pela apuração de condutas que transgridam as normas sanitárias, é comumente a vinculação à Vigilância Sanitária, a qual é popularmente reconhecida pelo “[...] exercício de poder

\footnotetext{
7 “Artigo 6 - S o direitos sociais a educaç o, a saúde, o tra alho, a moradia, o lazer, a segurança, a previd ncia social, a proteç o maternidade e inf ncia, a assist ncia aos desamparados, na forma desta Constituiç o" (CONSTITUI O DA REP LICA FEDERATI A DO RASIL DE 1988) Serv. Soc. \& Saúde, Campinas, SP v. 11, n. 2 (14) p. 223-244 jul./dez. 2012 ISSN 1676-6806
} 
de polícia sobre as atividades exercidas pelos particulares que digam respeito, de forma direta ou não com a saúde pública [...]" (CARVALHO; MACHADO E TIMM, 2004, p. 12).

De acordo com Dallari e Júnior (2010), o desempenho do papel de polícia sanitária ${ }^{8}$ está atrelado à abertura de um processo administrativo, o qual é instaurado a partir do descumprimento de normas sanitárias.

Contudo, a partir das considerações de Costa (2004), elucidamos que a atribuição da Vigilância Sanitária, apenas, como um órgão policialesco, configura-se como um reducionismo.

A autora sinaliza que o órgão de Vigilância tem a possibilidade de executar uma perspectiva de trabalho associada ao conceito de educação sanitária, o qual é definido como um conjunto de ações desenvolvidas com os sujeitos sociais - sejam consumidores, usuários de serviços de saúde, manipuladores de alimentos e outros produtos de interesse à saúde, profissionais/trabalhadores de saúde, entre outros - “[...] nas quais as informações sobre a produção social do complexo saúde-doença são trabalhadas visando contribuir na formação da consciência sanitária [...] e da participação social, resgatando-a para o campo das práticas de saúde coletiva [...]" (COSTA, 2004, p. 65).

A partir desta explanação, constata-se que as práticas de educação sanitária não se restringem ao âmbito da Vigilância Sanitária, mas sim ao conjunto de atividades desenvolvidas pela esfera da Vigilância em Saúde. De acordo com Artigo $2^{\circ}$ da Lei Municipal n. 13.725 de 09 de janeiro de 2004 - Códigos Sanitário do Município de São Paulo,

[...] entende-se por Vigilância em Saúde as ações de Vigilância Sanitária, Vigilância Epidemiológica, Vigilância em Saúde Ambiental e Vigilância em Saúde do Trabalhador ${ }^{9}$, que compõem um campo integrado e indissociável de práticas, fundado no conhecimento interdisciplinar e na ação intersetorial, desenvolvidos por meio de equipes multiprofissionais, com a participação ampla e solidária da sociedade, por intermédio de suas organizações, entidades e movimentos, estruturando, em seu conjunto, um campo de conhecimento.

\footnotetext{
${ }^{8}$ Salientamos ue o papel de pol cia pode ser desempenhado, $\mathrm{n}$ o somente, pela igil ncia Sanit ria. Serv. Soc.\& Saúde, Campinas, SP v. 11, n. 2 (14) p. 223-244 jul./ dez. 2012 ISSN 1676-6806
} 
Cabe salientar que o conceito de Vigilância se institui, no âmbito jurídico, somente a partir do texto Constitucional de 1988, no qual, o Artigo 200 dispõe como uma das principais atribuições do sistema de saúde: a fiscalização e inspeção de alimentos e bebidas; o controle e a fiscalização de elementos de interesse à saúde; bem como, a vigilância sanitária e epidemiológica.

Após a elucidação dos principais conceitos de saúde e vigilância, nos reportamos à fundamentação teórica referente ao Serviço Social enquanto profissão. Desse modo, para que o objeto de estudo fosse apreendido em sua concreticidade, tal pesquisa científica teve como embasamento a perspectiva crítico-dialética, que, a partir dos anos 1980, se insere no debate histórico e teórico-metodológico do Serviço Social, alicerçando o projeto ético-político, o Código de Ética profissional de 1993 e as Diretrizes Curriculares da Associação Brasileira de Ensino e Pesquisa em Serviço Social (ABEPSS). De acordo com Yazbek (2009, p.150 e 151),

[...] como matriz teórico-metodológica esta teoria (marxismo) apreende o ser social a partir de mediações. Ou seja, parte da posição de que a natureza relacional do ser social não é percebida em sua imediaticidade. [...] as relações sociais são sempre mediatizadas por situações, instituições etc., que ao mesmo tempo revelam/ocultam as relações sociais imediatas. Por isto nesta matriz o ponto de partida é aceitar os fatos, dados como indicadores, como sinais, mas não como fundamentos últimos do horizonte analítico.

Partindo deste referencial teórico, é mister vislumbrar que o delineamento do Serviço Social, no contexto da Vigilância em Saúde, foi analisado através da premissa de que a chamada questão social ${ }^{10}$ é o objeto de intervenção desta profissão, bem como “[...] a 'matéria-prima' e a justificativa da constituição do espaço do Serviço Social na divisão sócio técnica do trabalho e na construção/atribuição da identidade profissional" (YAZBEK, 2009, p. 129).

\footnotetext{
${ }^{9}$ Neste estudo não discorremos sobre a Vigilância em Saúde do Trabalhador, visto que o universo de pesquisa - Supervisão de Vigilância em Saúde (SUVIS) - é composto, apenas, pelas Vigilâncias Sanitária, Epidemiológica e Ambiental

10 “A questão social não é senão as expressões do processo de formação e desenvolvimento da classe operária e de seu ingresso no cenário político da sociedade, exigindo seu reconhecimento como classe por parte do empresariado e do Estado. É a manifestação, no cotidiano da vida social, da contradição entre proletariado e burguesia, a qual passa a exigir outros tipos de intervenção, mais além da caridade e repressão" (IAMAMOTO; CARVALHO, 1985, p. 77).

Serv. Soc. \& Saúde, Campinas, SP v. 11, n. 2 (14) p. 223-244 jul./dez. 2012 ISSN 1676-6806
} 


\section{METODOLOGIA}

Para que a execução da pesquisa ${ }^{11}$ estivesse em concordância com os objetivos propostos, foi mister a utilização de uma abordagem metodológica qualitativa, a qual, segundo Martinelli (1994), é evidenciada pela seguinte explicitação: "na verdade essa pesquisa tem por objetivo trazer à tona o que os participantes pensam a respeito do que está sendo pesquisado, não é só a minha visão de pesquisador em relação ao problema, mas é também o que o sujeito tem a me dizer a respeito" (ibid., p. 14).

A abordagem qualitativa utilizou-se do instrumental entrevista semiestruturada que, de acordo com Neto (1994), é a articulação de uma entrevista aberta, onde o informante aborda livremente o tema proposto, com uma entrevista estruturada, nesta as perguntas já estão previamente formuladas.

Partindo destas premissas, abordamos os seguintes questionamentos:

- Por que você escolheu a SUVIS e como se deu a sua inserção neste espaço?

- O que você pensa sobre a atuação profissional enquanto Autoridade Sanitária?

- Você consegue estabelecer uma relação direta entre o seu cotidiano de trabalho e as concepções teórico-metodológicas, técnico-operativas e ético-políticas do Serviço Social?

É importante destacar que a utilização do instrumental de entrevista semiestruturada possibilitou a abertura para outras questões, sendo que a descrita abaixo foi unânime entre os sujeitos:

- Você considera que a SUVIS seja um espaço de possibilidades para a categoria ou um processo de perda da identidade profissional?

Face ao exposto, o presente estudo selecionou seis assistentes sociais lotados nas SUVIS's de uma dada região da cidade de São Paulo ${ }^{12}$, contudo, um deles se recusou a participar da pesquisa.

${ }^{11}$ É relevante pontuar que a temática em questionamento foi sistematizada em um projeto de pesquisa, o qual foi remetido, juntamente com o Termo de Consentimento Livre e Esclarecido (TCLE), ao Comitê de Ética em Pesquisa (CEP) da Secretaria Municipal da Saúde da Prefeitura de São Paulo, ambos obtiveram parecer favorável em 20 de julho de 2010. Após a aprovação, o pesquisador responsável iniciou o processo de investigação.

${ }^{12}$ Inicialmente tínhamos a proposta de entrevistar um assistente social de cada região da cidade (norte, sul, leste, centro-oeste e sudeste), no entanto, tal procedimento não foi viabilizado, devido ao curto espaço temporal para a conclusão do trabalho, bem como a aprovação do projeto no Comitê de Ética em Pesquisa da Secretaria de Saúde.

Serv. Soc.\& Saúde, Campinas, SP v. 11, n. 2 (14) p. 223-244 jul./ dez. 2012 ISSN 1676-6806 
A primeira aproximação aos sujeitos realizou-se via correio eletrônico ou pessoalmente, na ocasião, os profissionais foram informados sobre a proposta, os procedimentos metodológicos e a necessidade de registro da entrevista em gravador digital, visto que os diálogos seriam transcritos na íntegra, a fim de que fosse preservada a autenticidade dos relatos.

Destacamos que as entrevistas foram realizadas nos meses de julho (após a aprovação do projeto no Comitê de Ética em Pesquisa) e agosto de 2010, sendo que tiveram uma média de duração de 25 minutos.

\section{RESULTADOS E DISCUSSÃO}

A análise e interpretação das informações obtidas nas entrevistas foram agrupadas em quatro categorias de análise ${ }^{13}$, da forma que se segue:

1- A inserção do profissional na SUVIS e as práticas de trabalho cotidianas

De acordo com o explicitado anteriormente, antes da inserção dos assistentes sociais concursados no ano de 2008, alguns outros profissionais já desenvolviam práticas cotidianas nas SUVIS's, sobretudo na Vigilância Sanitária e Epidemiológica.

Dois sujeitos entrevistados se situam neste perfil, um deles afirmou que escolheu a SUVIS's porque queria voltar a trabalhar na saúde. Já o outro pontuou que tinha contato com as questões teóricas da Vigilância, desse modo, procurou a SUVIS, pois queria vivenciar a inspeção sanitária na prática.

Foi observado que outro sujeito já compunha o quadro de profissionais da prefeitura e com a abertura de vagas do concurso de 2008 foi possibilitada a sua transferência para a SUVIS, o mesmo pontuou que escolheu este local porque queria mudar de espaço sócio ocupacional.

Este profissional sinalizou que a abertura de vagas, no ano de 2008, para profissionais de Serviço Social estava atrelada à intervenção com munícipes que possuem Transtorno Obsessivo Compulsivo (TOC) e acumulam materiais inservíveis em suas residências, neste sentido, podemos observar que a proposta inicial de trabalho estava vinculada à uma questão de Saúde Pública.

Conforme explicitado anteriormente, uma das intervenções da Vigilância Ambiental refere-se às vistorias zoossanitárias, as quais são desencadeadas através de

\footnotetext{
${ }^{13}$ Segundo Gomes (1994), a criaç o de categorias de an lises em pes uisa ualitativa, significa o agrupamento de elementos, ideias ou e press es em torno de um conceito único.

Serv. Soc. \& Saúde, Campinas, SP v. 11, n. 2 (14) p. 223-244 jul./dez. 2012 ISSN 1676-6806
} 
denúncias de munícipes ou de outros órgãos públicos, como o Ministério Público, nas quais são explicitadas situações de pessoas, muitas vezes de idosos sozinhos, que acumulam materiais inservíveis (recicláveis, lixo orgânico e etc) e/ou que possuem um número excessivo de animais (gatos e cachorros) em suas residências. A partir disso, começam a surgir insetos, roedores e condições higiênico-sanitárias insalubres que culminam em risco de Saúde Pública para a vizinhança e, inclusive, para o próprio morador e, em alguns casos, para os animais da residência em questão.

Inicialmente a equipe de vistoria zoossanitária era composta por um médico veterinário, um biólogo e/ou um agente de zoonoses, os quais se dirigiam à residência denunciada para averiguar o risco à saúde, no entanto, a abordagem ao munícipe era insatisfatória. Estes mesmos profissionais começaram a perceber que, possivelmente, estas pessoas poderiam ter algum transtorno mental, mais especificamente, o Transtorno Obsessivo Compulsivo (TOC). Desse modo, iniciou-se a discussão de que medidas meramente administrativas, como a imposição de multas, para que o munícipe eliminasse os focos de risco à saúde, eram insuficientes, visto que este usuário, possivelmente, não poderia responder sobre os seus atos, devido à questão de sua saúde mental.

Diante deste contexto, emergiu a possibilidade de inserção de um profissional de Serviço Social na equipe de vistoria zoossanitária, a fim de que este pudesse reconhecer a realidade social em que este usuário estava inserido, estabelecendo um fluxo de atendimento, entre a Unidade Básica de Saúde de referência e demais serviços assistenciais.

No entanto, esta proposta de trabalho específica não foi relatada durante a escolha de vagas para os profissionais concursados em 2008, suscitando-se a possibilidade de inserção em outras ações da Vigilância. Os profissionais pontuam que escolheram a vaga porque na apresentação da SUVIS informou-se, apenas, que o assistente social faria um trabalho com comunidade.

Após esta primeira indagação, os profissionais foram questionados como se deu a inserção neste lócus de trabalho. É interessante notar que dois assistentes sociais apontam que este processo suscitou um sentimento reflexivo:

Me causou muito estranhamento porque já veio a demanda do conhecer a Vigilância é: ir em bar, ir em mercado, em drogaria... [...] não, isso não é o nosso papel, não é a nossa intervenção [...] (SUJEITO 5) 
$\mathrm{Na}$ verdade, eu cheguei e fiquei assim muito, totalmente perdida, porque primeiro eu era nova na Saúde [...] e eu como assistente social, no começo eu fiquei, tipo... "o que eu estou fazendo aqui? Será que há algo específico que eu possa fazer na inspeção sanitária?" (SUJEITO 2)

A partir destas colocações, podemos evidenciar que a relação do Serviço Social com algumas ações interventivas, sobretudo na Vigilância Sanitária, é questionada pelos profissionais, na medida em que o trabalho em determinadas inspeções se reduz a visões meramente técnicas dos procedimentos de saúde - como a desinfecção e esterilização de materiais, as boas práticas na comercialização, armazenamento e preparo de alimentos e etc - portanto, não apresentam relações diretas com o objeto de intervenção da profissão, ou seja, a chamada questão social.

A seguir podemos notar duas tipologias de posicionamento profissional diante desta problemática. O primeiro sujeito discorre que procurou:

[...] entender primeiro o que era a Supervisão de Vigilância em Saúde [...] passei os dois primeiros meses construindo um plano de trabalho do Serviço Social e aí nele a gente colocava as possibilidades de intervenção [...] (SUJEITO 5)

Já o segundo sujeito encara este trabalho não como uma ação específica do Serviço Social:

[...] eu fui entendendo que todas as pessoas que estavam envolvidas ali, os profissionais mesmo sendo os profissionais da saúde... a gente tinha a mesma função que era de Autoridade Sanitária [...] eu estava me identificando com aquele tipo de trabalho, mas não como uma forma específica... como assistente social especificamente (SUJEITO 2)

Observamos que, de certa forma, a inserção do Sujeito 4 também se aproxima ao contexto vivenciado pelo Sujeito 2, pois o primeiro foi afastado do trabalho vinculado à Vigilância Ambiental para compor a equipe de Sanitária por conta do número insuficiente de técnicos. Sendo assim, este profissional, assim como o Sujeito 4, inicia e tem desenvolvido as suas atividades em todas as áreas de inspeção, independente de uma possível relação com o Serviço Social.

Os profissionais 5 e 1 relatam que tem desenvolvido atividades nas Vigilâncias Ambiental e Sanitária, sendo que na primeira executam intervenções referente às vistorias zoossanitárias, além de trabalhos de educação em saúde em comunidades. Já 
na Vigilância Sanitária compõem as equipes que fiscalizam as Instituições de Longa Permanência para Idosos (ILPI's) e creches ${ }^{14}$.

Por fim, o Sujeito 3 expõe uma inserção diferenciada dos demais profissionais, pois inicia os seus trabalhos na Vigilância Epidemiológica e atualmente gerencia o programa de controle de tuberculose.

O programa todo começa quando tem uma ficha de notificação e ela só é realizada quando tem um caso confirmado de tuberculose [...] Quando chega na Vigilância Epidemiológica essa ficha, aí desencadeia um monte de processo [...] essas ações seriam: entrar em contato com a Unidade Básica mais próxima, pedir uma Visita Domiciliar, através dessa VD ir atrás desse paciente, dos comunicantes desse paciente e para tentar investigar o foco, de onde esse paciente poderia ter sido contaminado, quem é o foco de transmissão. E a partir daí, também não perder de vista esse paciente, para poder acompanhá-lo durante seis meses. (SUJEITO 3)

O Sujeito 3 também nos discorre que o programa desenvolve ações de busca ativa de pacientes com tuberculose em instituições fechadas, como Penitenciárias, em Unidades Básicas de Saúde e nos Programas de Saúde da Família. Além disso, nos relata a existência de avaliações e encontros/fóruns de discussões.

\section{O papel de autoridade sanitária}

Conforme observado anteriormente, o papel de Autoridade Sanitária tem sido uma função desempenhada, majoritariamente, pelos profissionais de Serviço Social que estão lotados na Vigilância Sanitária, desse modo, faz-se mister compreender quais são as atribuições deste papel ${ }^{15}$.

De acordo com o inciso VII do Artigo $7^{\circ}$ do Decreto Municipal no 50.079 de 07/10/2008, a inspeção sanitária é um

[...] procedimento técnico realizado pela autoridade sanitária em estabelecimento ou equipamento de interesse à saúde, com o objetivo de identificar e intervir sobre os riscos à saúde da população, presentes na produção e circulação de mercadorias, na prestação de serviços e

\footnotetext{
${ }^{14}$ Devemos elucidar ue o tra alho dos assistentes sociais no $\mathrm{m}$ ito das Instituiç es de Longa Perman ncia para Idosos desenvolvido, conjuntamente, com uma e uipe multidisciplinar ( $\mathrm{m}$ dico, enfermeiro, farmac utico, e etc.) ue fiscaliza o tipo de atendimento prestado por esses serviços. A vistoria fundamentada nas disposiç es presentes no $\mathrm{C}$ digo Sanit rio do Munic pio de S o Paulo, na Lei 10.741/03 (Estatuto do Idoso) e na Resoluç o de Diretoria Colegiada (RDC) n 283/05 da Ag ncia Nacional de igil ncia Sanit ria, a ual regulamenta as normas de atendimento em Instituiç es de Longa Perman ncia espec ficas para idosos. Em relaç o s creches, os profissionais se fundamentam nas disposiç es esta elecidas pelo Estatuto da Criança e do Adolescente (ECA) Lei Federal n 8.069, de 13 de julho de 1990.

${ }^{15}$ Devemos salientar ue em sua pr tica profissional o Sujeito $3 \mathrm{n}$ o e erce o papel de Autoridade Sanit ria. Serv. Soc.\& Saúde, Campinas, SP v. 11, n. 2 (14) p. 223-244 jul./ dez. 2012 ISSN 1676-6806
} 
no meio ambiente, inclusive o de trabalho, mediante a avaliação de processos que garantam produtos, serviços e ambientes seguros e saudáveis.

Neste sentido, o Artigo $5^{\circ}$ deste mesmo Decreto dispõe que "o Secretário Municipal de Saúde credenciará como autoridade sanitária servidores públicos de nível universitário, lotados na Secretaria Municipal da Saúde”.

As autoridades sanitárias, conforme o Artigo 97 da Lei Municipal no 13.725 de 09/01/04, são os profissionais “[...] competentes para fazer cumprir as leis e regulamentos sanitários, expedindo termos, autos de infração e de imposição de penalidades, referentes à prevenção e controle de tudo quanto possa comprometer a saúde". É relevante salientar que o $\$ 3^{\circ}$ do Artigo $101^{\circ}$ desta Lei discorre que a relação dos agentes fiscalizadores deve ser publicada, semestralmente, em Diário Oficial da Cidade de São Paulo, “[...] para fins de divulgação e conhecimento pelos interessados, ou em menor prazo, a critério da autoridade sanitária competente, e por ocasião de exclusão e inclusão dos membros da equipe de vigilância sanitária”.

A partir destas considerações, os sujeitos desta pesquisa foram indagados sobre a atuação enquanto Autoridade Sanitária. Podemos destacar:

A questão de ser Autoridade Sanitária foi algo imposto, não foi uma escolha de você quer ou não ser... a partir do momento que eu estava na Sanitária foi falado assim... Olha você vai sair em "Diário Oficial". (SUJEITO 1)

Face ao exposto, evidenciamos que os assistentes sociais concursados em 2008 não foram previamente orientados de que os profissionais lotados na Vigilância Sanitária, obrigatoriamente, conforme disposto nas legislações supracitadas, devem ser nomeados como Autoridade Sanitária a fim de que desempenhem todas as atividades pertinentes a esta área.

Outro sujeito revela um fator relevante:

Eu acho que é um trabalho, é um trabalho novo e a gente acaba entrando como técnico, sem levar muito em conta a sua categoria profissional [...] A gente acaba sendo tarefeira, de ficar fazendo vistoria, relatório, de autuar, de receber, requisitar, reinspeção, cobrar... aí não dá tempo de discutir as particularidades de cada profissão. E isso não é só com o assistente social, mas também com médicos, enfermeiras... a gente acaba exercendo a tarefa de Autoridade Sanitária mesmo, não tem jeito. (SUJEITO 4)

O depoimento do profissional supracitado nos faz refletir sobre uma tendência que assola um número significativo de assistentes sociais, em diversificadas áreas de 
intervenção, a qual se materializa no desempenho burocrático e rotineiro das atividades, ou seja, "[...] que reduz o trabalho do assistente social a mero emprego, como se esse se limitasse ao cumprimento burocrático do horário, à realização de um leque de tarefas as mais diversas, ao cumprimento de atividades preestabelecidas" (IAMAMOTO, 2006, p. 21).

Diante da execução de atividades que não estão atreladas à formação profissional, questionamos os sujeitos se houve alguma capacitação para a atuação nesta dinâmica de trabalho. A resposta para tal questão foi negativa.

No decorrer das entrevistas foi pontuado por um dos sujeitos o receio em ser Autoridade Sanitária, uma vez que isto implica a execução de intervenções em todas as áreas monitoradas pela Vigilância, independente do perfil profissional.

\section{A relação Serviço Social e Supervisão de Vigilância em Saúde}

Inicialmente devemos salientar que a inserção do assistente social na área da "Saúde" está atrelada à ampliação deste conceito, em 1948, pela Organização Mundial da Saúde (OMS), o qual passa a ser compreendido através dos aspectos biopsicossociais.

Tal ampliação é corroborada pelo disposto na Constituição Cidadã de 1988, na qual, em seu Artigo 196, é preconizado que a "saúde é direito de todos e dever do Estado, garantido mediante políticas sociais e econômicas que visem à redução do risco de doença e de outros agravos e ao acesso universal e igualitário às ações e serviços para a sua promoção, proteção e recuperação".

A caracterização do assistente social como um profissional da saúde é sustentada pela Resolução $n^{\circ}$ 218, de 06/03/1997, do Conselho Nacional de Saúde, e pela Resolução CFESS (Conselho Federal de Serviço Social) no 383, de 29/03/1999. Esta última Resolução também destaca que "atribui-se ao assistente social, enquanto profissional de saúde, a intervenção junto aos fenômenos socioculturais e econômicos que reduzam a eficácia dos programas de prestação de serviços nos níveis de promoção, proteção e/ou recuperação da saúde"

Partindo para o problema/objeto de investigação desta pesquisa, vislumbramos que a presente categoria se evidenciou como um eixo relevante para identificarmos uma possível interconexão entre as práticas cotidianas, delineadas na primeira categoria de análise, o papel de Autoridade Sanitária e o próprio Serviço Social enquanto profissão. Serv. Soc.\& Saúde, Campinas, SP v. 11, n. 2 (14) p. 223-244 jul./ dez. 2012 ISSN 1676-6806 
Desse modo, os sujeitos foram questionados se conseguem estabelecer uma relação direta entre o seu cotidiano de trabalho e as concepções teórico-metodológicas, técnico-operativas e ético-políticas do Serviço Social.

$\mathrm{Eu}$ acho que sim, porque toda aquela parte de documentação, de relatórios, de visitas... tudo isso eu faço gerenciando, a única diferença é que eu não tenho mais aquele contato direto com o cliente, usuário, paciente... [...] mas eu acho que dá sim, porque eu continuo fazendo as ações educativas, os treinamentos [...] a gente faz toda essa parte de levantamento para poder construir o perfil dessa realidade [...] (SUJEITO 3)

A fala do Sujeito 3 atrelada à contextualização das práticas desenvolvidas na Vigilância Epidemiológica, nos permite uma identificação com as colocações de Teixeira (2009, p. 554), a qual nos elucida o avanço do Serviço Social para o "[...] complexo campo da formulação, gestão e avaliação de políticas públicas, planos, programas e projetos sociais, impondo a apropriação de conceitos e procedimentos para a atuação nesse largo e diversificado espectro de relações de gestão [...]". Concomitantemente, destaca-se a ampliação do fazer profissional, para além da atribuição socialmente/historicamente construída para o assistente social, ou seja, na ação direta com o usuário.

Os Sujeitos 1 e 5, lotados na Vigilância Sanitária e Ambiental, também conseguem estabelecer uma relação entre as práticas cotidianas e a profissão.

No caso de uma Instituição de Longa Permanência para Idoso, se eu vejo alguma violação de direitos dos idosos, a forma de viabilizar isso, além de ser assistente social, por ser Autoridade Sanitária e de estar na SUVIS, é fazer um Auto de Infração colocando o Estatuto do Idoso, colocando as legislações sociais além das sanitárias e a questão do olhar enquanto aquele idoso não só parte físico-estrutural daquele estabelecimento... o assistente social vem para esse novo olhar de entrar em contato com o Ministério Público, de fazer a denúncia, de ir atrás desses direitos. (SUJEITO 1)

Na Ambiental [...] lá ficou mais claro o papel do Serviço Social do que na Vigilância Sanitária. A nossa inserção na Vigilância Ambiental foi através das vistorias zoossanitárias [...] (SUJEITO 5)

Por outro lado, observamos que dois profissionais mostraram dificuldades em identificar essa relação. Um deles discorre que o olhar meramente técnico em saúde, durante a realização das vistorias, não possibilita a relação Serviço Social - Vigilância. 


\section{A identidade profissional nesta dinâmica}

No decorrer das entrevistas, partindo das concepções pontuadas pelos sujeitos, suscitou-se o questionamento se a SUVIS seria um espaço de possibilidades para a categoria ou um processo de perda da identidade profissional, visto que, de acordo com o explicitado anteriormente, algumas práticas cotidianas não estão diretamente atreladas ao objeto de intervenção do Serviço Social. Por conseguinte, todos os assistentes sociais foram abordados por tal indagação.

[...] é um espaço de possibilidades sim, e muitas [...] na própria Ambiental com esse trabalho com comunidade, tinha uma lacuna mesmo que os próprios veterinários que faziam vistoria zoossanitária falaram [...] da necessidade desse profissional que faça esse link com a Unidade Básica, que dê prosseguimento aos casos [...] e o assistente social com todo o entendimento de realidade que ele tem, ele contribui para isso, que é um saber específico nosso. (SUJEITO 1)

O Sujeito 4 também relata que considera a SUVIS um espaço de possibilidades, contudo, argumenta que a inserção de somente um assistente social, em cada setor, dificulta a construção do trabalho específico, visto que não há espaços de discussão dessas práticas. Como alternativa, o sujeito sugere a implementação de uma Supervisão de Serviço Social exclusiva para os profissionais lotados nas SUVIS's.

$\mathrm{O}$ apontamento levantado pelo profissional evidencia um dos principais desafios para os assistentes sociais atualmente, o qual se explicita na "[...] capacidade de decifrar a realidade e construir propostas de trabalho criativas e capazes de preservar e efetivar direitos [...]" (IAMAMOTO, 2006, p. 20).

Acreditamos que a construção de espaços coletivos para a discussão destas novas inserções se materializa como uma alternativa para rompermos com a visão endógena e focalista que, segundo Iamamoto (2006), aprisiona os assistentes sociais em seus "muros internos". No entanto, concomitantemente, é necessário o fortalecimento individual destes sujeitos, a partir de uma formação profissional de qualidade que desmistifique o real significado e as contradições intrínsecas da profissão.

Já o Sujeito 5 nos traz um ponto importante. Primeiramente, o profissional relata que o trabalho desenvolvido na SUVIS, a partir das vistorias zoossanitárias e do trabalho em comunidades na Vigilância Ambiental, bem como a inserção na equipe de Instituições de Longa Permanência para Idosos e creches na Sanitária, constitui-se em possibilidades para o Serviço Social. Entretanto, o Sujeito aponta que esta mesma 
construção não tem se efetivado em grande parte das SUVIS's do município de São Paulo.

[...] falando o município de São Paulo eu vejo como um grande problema, uma questão de perda da identidade sim, por que? Primeiro, quando você conversa com o povo do município, eles não sabem o que o assistente social faz e a imagem que eles têm do assistente social é daquela que vai estar fazendo o bar, que vai estar fazendo qualquer coisa $[\ldots]$ (SUJEITO 5)

Corroborando a colocação do Sujeito 5, o profissional 2 pontua da seguinte forma:

Eu não tenho dúvida de que é um processo de perda da identidade como ela é hoje [...] Na verdade a gente não tem um espaço específico que a gente possa ser compreendido, respeitado ou visto como um profissional a contribuir, a gente é mais uma Autoridade Sanitária.

Por fim, de acordo com os sujeitos, a construção da identidade profissional atrelada à fundamentação teórico-prática do Serviço Social também se esbarra na relação com os demais profissionais das equipes, uma vez que estes não compreendem a especificidade do Serviço Social. Diante disto, sustentam a premissa de que o assistente social, como qualquer outro membro da equipe, está habilitado a responder por todas as áreas da Vigilância.

\section{CONSIDERAÇÕES FINAIS}

Inicialmente devemos pontuar que a discussão proposta neste trabalho evidenciou-se como uma primeira apropriação ao binômio Serviço Social e Vigilância em Saúde, portanto, como em qualquer área das Ciências Humanas, não nos sustentamos em verdades absolutas, mas sim, em constantes aproximações à concreticidade do real (KOSIK, 2002).

A partir dos relatos apontados pelos sujeitos, observamos que em relação ao objetivo geral deste estudo - apontar como se delineia a identidade profissional dos assistentes sociais inseridos nas SUVIS's - há duas proposições.

Primeiramente constatamos que a construção desta identidade está atrelada ao tipo de intervenção cotidiana realizada pelos profissionais.

A SUVIS pode ser um espaço de possibilidades para a categoria, se as ações desenvolvidas reproduzirem as atribuições e competências específicas do Serviço Social, as quais, de acordo com o descrito ao longo deste estudo, estão relacionadas com 
as manifestações das contradições intrínsecas de uma sociedade que se reproduz através da exploração do homem pelo homem e que, segundo Iamamoto (2009), através da luta pela afirmação dos direitos também encontra a luta contra a exploração pelo capital.

Tais atribuições e competências ainda estão dispostas, sobretudo, na Lei Federal n. 8.662 de 07/06/1993 e na Resolução CFESS n. 273 de 13/03/1993 - Código de Ética Profissional do Assistente Social.

Deste modo, os assistentes sociais que buscam a intersecção Serviço Social e Vigilância em Saúde estão em processo e/ou já identificaram as possibilidades e os limites inerentes a esta dinâmica, concomitantemente, os mesmos também estão construindo as suas identidades ${ }^{16}$ - lembrando que estas estão em incessante movimento e transformação, pois, de acordo com Martinelli (2009), são unidades que pulsam conforme as determinações políticas, sociais, econômicas, históricas e culturais.

Por outro lado, no espaço da SUVIS, vislumbramos posturas que reproduzem tarefas aleatórias impostas pela cotidianidade, independente de uma provável aproximação aos pressupostos teórico-metodológicos, ético-políticos e técnicooperativos desta Ciência Social Aplicada. Logo, podemos afirmar que nestes casos há um distanciamento da identidade profissional enquanto assistente social, sendo que o sujeito se identifica como um profissional polivalente cuja atribuição remete, exclusivamente, à imposição da legislação sanitária no decorrer de uma fiscalização em qualquer estabelecimento de interesse à saúde e/ou no gerenciamento de programas/ações referentes ao processo saúde-doença-ambiente.

É relevante esclarecermos que o presente trabalho não teve a intenção de depreciar tais posturas, visto que as mesmas são resultado de um constante movimento das diversificadas esferas da vida cotidiana, desse modo, não devem ser reduzidas, apenas, ao comportamento específico do profissional.

No que concerne aos objetivos específicos desta pesquisa, destacamos que a inserção dos assistentes sociais nas SUVIS's, a priori, apresentou alguma indicação, contudo, esta proposta não foi sistematizada em um plano de trabalho específico para a profissão, tal lacuna repercute da forma que se segue.

Em relação às ações desenvolvidas atualmente pelos profissionais, destacamos aquelas desconectadas do saber específico do Serviço Social - como as relativas aos

\footnotetext{
16 “... mais do ue perguntar por identidade devemos nos perguntar por identidades, por processos de identificaç o em curso, pois as identidades s o, fundamentalmente, condiç o de ser e possi ilidade, s o perman ncias, e s o transformaç es" (MARTINELLI, 2009, p. 03).

Serv. Soc.\& Saúde, Campinas, SP v. 11, n. 2 (14) p. 223-244 jul./ dez. 2012 ISSN 1676-6806
} 
procedimentos meramente técnicos em saúde, isto é, a execução das Boas Práticas no armazenamento, processamento de alimentos, esterilização/desinfecção de materiais, além da própria apreensão da saúde, apenas, sob o espectro da doença em si - e aquelas referentes às ações que vislumbram a saúde como “[...] direito de todos e dever do Estado, garantido mediante políticas sociais e econômicas que visem à redução do risco de doença e de outros agravos [...]" (CONSTITUIÇÃO FEDERAL de 1988, Art. 196)

Adentrando a cotidianidade das SUVIS's, evidenciamos que alguns planos e programas podem ser devidamente apropriados pelos profissionais de Serviço Social, uma vez que esta profissão possui como um de seus princípios fundamentais a garantia dos direitos civis, sociais e políticos das classes trabalhadoras. Desse modo, a saúde, caracterizada como um direito social, está estritamente vinculada às diretrizes da profissão e, por conseguinte, a Vigilância, enquanto um instrumento de operacionalização do chamado Direito Sanitário, também está atrelada a este princípio fundamental do Serviço Social.

Além da profissão estabelecer conexões com as políticas de saúde, podemos elencar que o assistente social, devido à sua formação essencialmente investigativa e interventiva, é o profissional capacitado para promover leituras de realidade concretas que vislumbram as manifestações da questão social para além de uma única política pública.

Isto pode ser evidenciado na questão do idoso institucionalizado, no serviço prestado por uma unidade escolar e nos determinantes sociais e ambientais que repercutem no processo saúde-doença. A intervenção qualitativa sobre estas dinâmicas requer a interface entre os direitos sociais dispostos na Constituição de 1988, quais sejam: saúde, assistência e previdência social, moradia, educação, trabalho, segurança e lazer.

Em relação ao segundo objetivo específico deste trabalho - compreender a construção histórica da identidade profissional dos assistentes sociais - vislumbramos, a partir das considerações de Martinelli (2009) que o Serviço Social, em sua gênese, não participou diretamente do processo de construção de sua identidade, visto que esta foi atribuída, conforme as necessidades de reprodução do capital.

Contudo, devido ao incessante movimento da unidade "identidades" (MARTINELLI, 2009), podemos corroborar que, a partir do Movimento de Reconceituação e da diretriz expressada no projeto ético-político hegemônico da Serv. Soc. \& Saúde, Campinas, SP v. 11, n. 2 (14) p. 223-244 jul./dez. 2012 ISSN 1676-6806 
categoria, o Serviço Social, atualmente, vem se apropriando e delineando um processo de decodificação destas identidades.

Diante dos questionamentos e das apreensões elencadas nesta pesquisa, constatamos que se faz mister novas aproximações a este cenário a fim de que sejam, conforme Iamamoto (2006), desveladas as possibilidades que estão dadas na realidade, mas que não são automaticamente transformadas em alternativas profissionais.

Por conseguinte, é imprescindível a organização de fóruns de discussão entre os assistentes sociais inseridos neste contexto, bem como entre as equipes multiprofissionais que compõem o processo de Vigilância. Ressaltamos que não devemos negar o espaço da SUVIS, mas cabe aos assistentes sociais e aos gestores apropriarem-se das especificidades do Serviço Social para transformá-las em projetos e frentes de trabalho que preconizem a qualidade do serviço prestado em Vigilância em Saúde.

\section{REFERÊNCIAS}

AITH, F. M. A. Curso de direito sanitário: a proteção do direito à saúde no Brasil. São Paulo: Quartier Latin, 2007.

BRASIL. Constituição da República Federativa do Brasil: promulgada em 05 de outubro de 1988. Brasília, DF: Senado Federal, 1988

BRASIL. Lei no 8.069, de 13 de julho de 1990. Dispõe sobre o Estatuto da Criança e do Adolescente e dá outras providências.

BRASIL. Lei $\mathbf{n}^{\mathbf{0}} \mathbf{8 . 0 8 0}$, de 19 de setembro de 1990. Dispõe sobre as condições de promoção e recuperação da saúde, a organização e o financiamento dos serviços correspondentes e dá outras providências.

BRASIL. Lei no 8.142, de 28 de dezembro de 1990. Dispõe sobre a participação da comunidade na gestão do Sistema Único de Saúde - SUS - e sobre as transferências intergovernamentais de recursos financeiros na área da saúde e dá outras providências.

BRASIL. Lei $\mathbf{n}^{\mathbf{0}} \mathbf{1 0 . 7 4 1}$, de $1^{\text {o }}$ de outubro de 2003. Dispõe sobre o Estatuto do Idoso e dá outras providências.

BRASIL. Ministério da Saúde. Secretaria de Vigilância em Saúde. Manual de direito sanitária com enfoque na vigilância em saúde. Brasília: Ministério da Saúde, 2006. 
BRASIL. Resolução da Diretoria Colegiada (RDC), da Agência Nacional de Vigilância Sanitária, $\mathbf{n}^{\mathbf{0}}$ 283, de 26 de setembro de 2005. Define normas de funcionamento para as Instituições de Longa Permanência para Idosos, de caráter residencial.

CARVALHO, C. MACHADO, R. B.; TIMM, L. B. Direito Sanitário Brasileiro. São Paulo: Quartier Latin, 2004.

CONSELHO FEDERAL DE SERVIÇO SOCIAL. Lei de Regulamentação da Profissão de Assistente Social. Lei $n^{\circ}$ 8.662, de 07 de junho de 1993. Dispõe sobre a profissão de Assistente Social e dá outras providências.

CFESS. Código de Ética Profissional dos Assistentes Sociais. Resolução CFESS $n^{\circ}$ 273, de 13 de março de 1993 com as alterações introduzidas pelas Resoluções CFESS $n^{\circ} 290 / 04$ e no $239 / 94$.

CFESS. Resolução CFESS no 383, de 29 de março de 1999. Caracteriza o assistente social como profissional da saúde.

CFESS. Parâmetros para a atuação de assistentes sociais na saúde. Grupo de Trabalho Serviço Social na Saúde. Brasília, março de 2009.

CONSELHO NACIONAL DE SAÚDE. Resolução nº 218, de 06 de março de 1997. COSTA, E.A. Vigilância Sanitária: proteção e defesa da saúde. 2 ed. São Paulo: Sociedade Brasileira de Vigilância de Medicamentos, 2004.

DALLARI, S. G.; JÚNIOR, V. S. N. Direito Sanitário. São Paulo: Editora Verbatim, 2010 .

GOMES, R. A análise de dados em pesquisa qualitativa. In: MINAYO, M.C. Pesquisa social: teoria, método e criatividade. 23.ed. Petrópolis, RJ: Vozes, 1994, cap. 4, p. 6780.

IAMAMOTO, M.V.; CARVALHO, R. Relações sociais e Serviço Social: esboço de uma interpretação histórico-metodológica. 4.ed. São Paulo: Cortez, 1985.

IAMAMOTO, M. V. O Serviço Social na cena contemporânea. Serviço Social: direitos sociais e competências profissionais. Brasília: CFESS/ABEPSS, 2009. p. 15-50.

IAMAMOTO, M. V. O Serviço Social na contemporaneidade: trabalho e formação profissional. 10.ed. São Paulo: Cortez, 2006.

KOSÍK, K. Dialética do concreto. 7.ed. Rio de Janeiro: Paz e Terra, 2002.

MARTINELLI, M.L. A pergunta pela identidade profissional do Serviço Social: uma matriz de análise. 2009. 


\section{MARTINELLI, M.L. O uso de abordagens qualitativas na pesquisa em serviço} social: um instigante desafio. In: PUC-SP. Núcleo de Estudos e Pesquisas sobre Identidade. 2.ed. São Paulo: Renovada; 1994. Cadernos do NEPI. v. 1. MARTINELLI, M.L. Serviço Social: identidade e alienação. 14.ed. São Paulo: Cortez, 2009.

NETO, O.C. O trabalho de campo como descoberta e criação. In: MINAYO, M. C. S. Pesquisa social: teoria, método e criatividade. 23.ed. Petrópolis, RJ: Vozes, 1994, cap. 3, p. 51-66.

SÃO PAULO (CIDADE). Decreto $\mathbf{n}^{\mathbf{0}} \mathbf{5 0 . 0 7 9}$, de 07 de outubro de 2008. Regulamenta disposições da Lei no 13.725/04, que institui o Código Sanitário do Município de São Paulo; dispõe sobre o Sistema Municipal de Vigilância em Saúde, disciplina o Cadastro Municipal de Vigilância em Saúde, estabelece os procedimentos administrativos de vigilância em saúde, altera a denominação do Departamento de Inspeção Municipal de Alimentos - DIMA e revoga o Decreto ${ }^{\circ}$ 44.577/04.

SÃO PAULO (CIDADE). Lei Municipal no 13.725, de 09 de janeiro de 2004. Institui o Código Sanitário do Município de São Paulo.

TEIXEIRA, J. B. Formulação, administração e execução de políticas públicas. Serviço Social: direitos sociais e competências profissionais. Brasília: CFESS/ABEPSS, 2009. p. 553-574.

YAZBEK, M. C. Fundamentos históricos e teórico-metodológicos do Serviço Social. In: Serviço Social: direitos sociais e competências profissionais. Brasília: FESS/ABEPSS, 2009. p. 143-164.

YAZBEK, M. C. O significado sócio histórico da profissão. In: CFESS/ABEPSS. Serviço Social: direitos sociais e competências profissionais. Brasília: CFESS/ ABEPSS, 2009. p. 125- 142. Disponível em: <http://www.prefeitura.sp.gov.br/cidade/secretarias/saude/vigilancia_em_saude/control e_de_zoonoses/vistoria_zoosanitaria/index.php?p=4160> Acesso em: 14/05/2010 
